\title{
Functionalized gold nanoparticles for the binding, stabilization, and delivery of therapeutic DNA, RNA, and other biological macromolecules
}

This article was published in the following Dove Press journal:

Nanotechnology, Science and Applications

17 September 2010

Number of times this article has been viewed

\author{
Robert K DeLong' \\ Christopher M Reynolds' \\ Yaneika Malcolm' \\ Ashley Schaeffer' \\ Tiffany Severs ${ }^{2}$ \\ Adam Wanekaya ${ }^{2}$ \\ 'Department of Biomedical Science \\ (Cell and Molecular Biology Program), \\ ${ }^{2}$ Department of Chemistry, Missouri \\ State University, Springfield, MO, USA
}

Correspondence: Robert K DeLong

Department of Biomedical Science (Cell and Molecular Biology Program), Missouri State University, Springfield, MO 65897, USA

Email robertdelong@missouristate.edu

\begin{abstract}
Nanotechnology has virtually exploded in the last few years with seemingly limitless opportunity across all segments of our society. If gene and RNA therapy are to ever realize their full potential, there is a great need for nanomaterials that can bind, stabilize, and deliver these macromolecular nucleic acids into human cells and tissues. Many researchers have turned to gold nanomaterials, as gold is thought to be relatively well tolerated in humans and provides an inert material upon which nucleic acids can attach. Here, we review the various strategies for associating macromolecular nucleic acids to the surface of gold nanoparticles (GNPs), the characterization chemistries involved, and the potential advantages of GNPs in terms of stabilization and delivery.

Keywords: gold, nanoparticles, nanomaterials, RNA, nucleic acid
\end{abstract}

\section{Introduction}

The ability of gold nanoparticles (GNPs) to interact with and enter cells has encouraged researchers to attach various compounds and biological macromolecules to gold in an effort to combine functionality with transport. Realization that GNPs can potentially stabilize and protect DNA, RNA, and other conjugates in solution proposes additional benefits over multistep methods that require separate approaches to delivery and stabilization. Excitement over the potential of GNPs has spurred research in many directions, which in addition to gene and RNA stabilization and delivery include a diversity of applications in materials science and sensor technologies as summarized in Figure 1.

For example, it is now possible to manipulate GNPs to detect extremely small concentrations of analyte, ${ }^{1}$ serve as scaffolds for 2- and 3-dimensional constructs, ${ }^{2}$ and behave as real-time observable nodes for imaging studies. ${ }^{3}$ In terms of biomedical applications for GNPs, nanotechnology is poised to finally deliver upon its promise to transform the face of molecular medicine, as evidenced by its existence in clinical trials on human subjects. ${ }^{4}$

This review focuses on the recent literature for the use of GNPs as delivery agents and their association and advantages in combination with biomacromolecules, particularly proteins, DNA, and RNA for potential biomedical applications. The discussion begins with functionalization of GNPs and the chemical functional groups used to produce derivatives for the purpose of such biomolecular interactions. The topic continues with characterization chemistries, spectroscopic techniques, and methods to study the conjugates formed between the GNPs and the biomolecules. Finally, the applications of these conjugates, particularly their ability to stabilize and deliver DNA and more recently RNA, are discussed. 


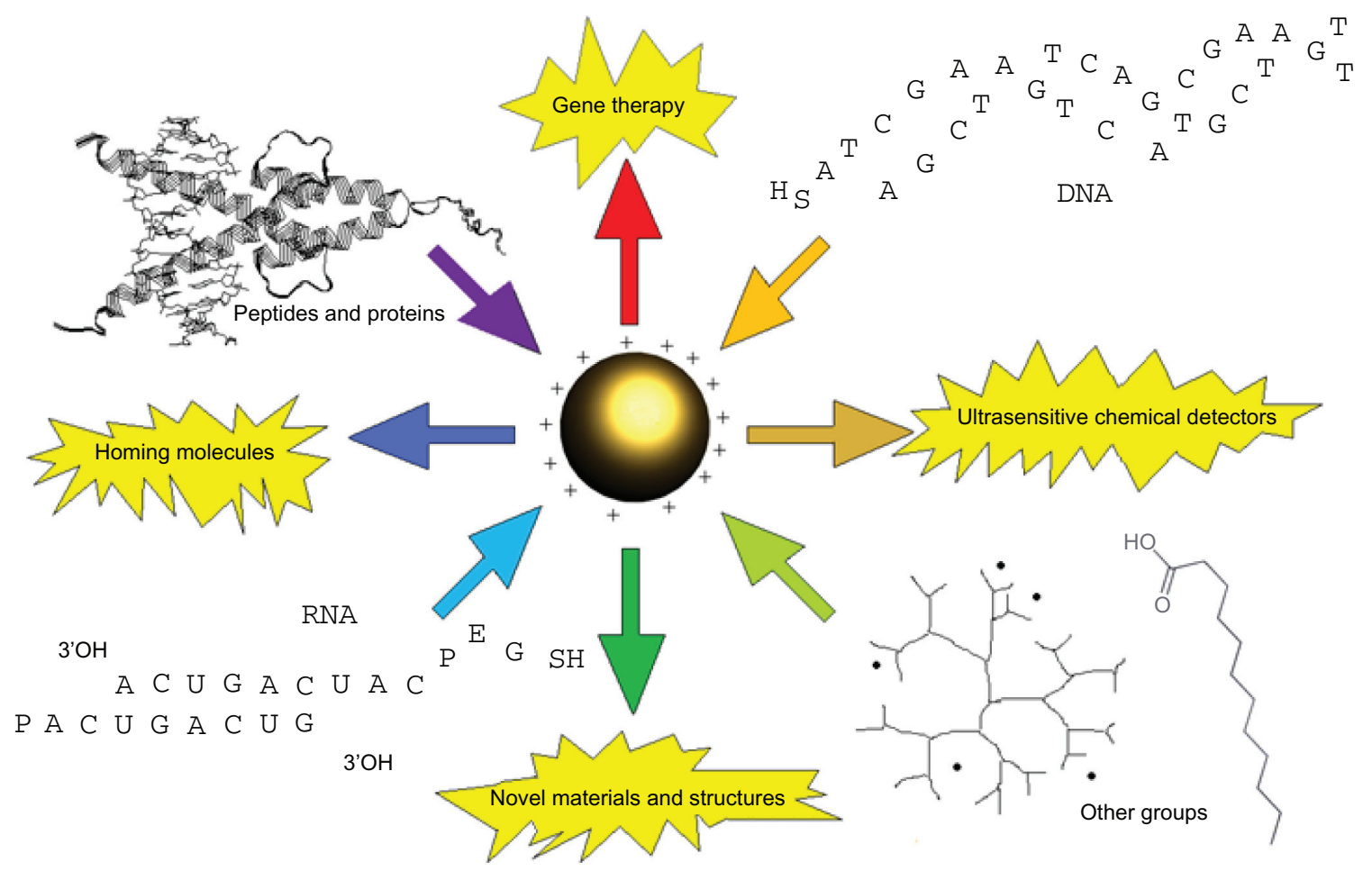

Figure I Graphical abstract designed to highlight various applications of gold nanoparticles with different kinds of macromolecule conjugates, such as thioalkylated DNA," RNA, ${ }^{90}$ proteins, ${ }^{24}$ peptides, ${ }^{45}$ carboxylic acids, ${ }^{8}$ and poly(amidoamine) (PAMAM) dendrimers. ${ }^{9}$

\section{Functionalization strategies and chemistries}

Functionalization of nanoparticles is necessary for their stability, functionality, and biocompatibility. The ultimate goal in functionalization is to preserve the properties of the GNP and the bound biological molecule. In other words, the biological molecule should be stable and able to retain its biorecognition properties and GNPs should be able to retain their unique properties such as strong plasmon absorption bands, ${ }^{5}$ light scattering, ${ }^{6}$ etc. For biomedical applications, surface-functionalization of GNPs is essential in order to target them to specific disease areas and allow them to selectively interact with cells or biological molecules. In general, functionalization of GNPs can be performed by either using chemical functional groups or biological molecules.

\section{Chemical functional groups}

Colloidal GNPs are normally stabilized against aggregation by using long hydrocarbon ligand chains consisting of various functional groups. One end of these molecules is adsorbed on the gold surface, whereas the other end points towards the solution, as shown in Figure 2 for the adsorption of mercaptocarboxylic acid molecules on a GNP surface. In the case of water-soluble nanoparticles, these functional groups are often carboxylic acids which stabilize the nanoparticles by electrostatic repulsion and can be exploited for the conjugation of other molecules to the particles. The choice of ligand depends on the particle size and the solvent. These ligands can also be used as anchor points for further attachment of biological molecules which will be demonstrated in the following section. Mercaptocarboxylic acids are popular in the stabilization of GNPs due to the strong affinity of sulfur for gold. ${ }^{7,8}$

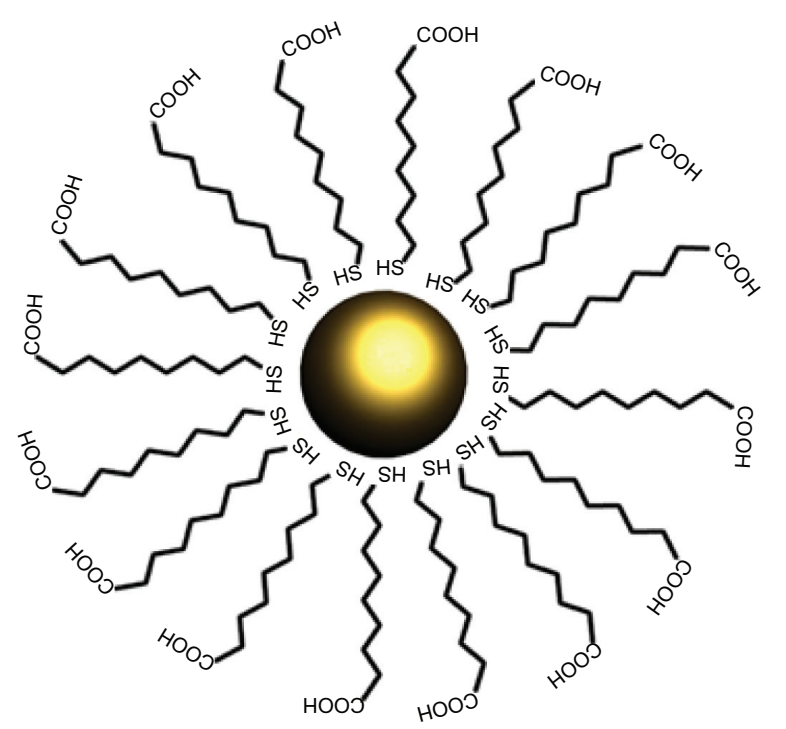

Figure 2 Chemisorption of mercaptocarboxylic acid chains on a gold nanoparticle surface. 
Polyethylene glycol (PEG) is also used as a ligand, as it provides colloidal stability because nanoparticles with PEG brushes on their surfaces repel each other for steric reasons. ${ }^{9}$ The use of PEG as a ligand enables the fabrication of unusually robust, water-soluble GNPs that do not aggregate even under extreme $\mathrm{pH}$ and ionic strength conditions or in the presence of proteins. In some cases, it may be necessary to change the ligand. Ligand exchange is motivated by several aspects: (1) the transfer of GNPs from an aqueous to an organic phase (and vice versa) and (2) by exchanging hydrophilic surfactants with hydrophobic surfactants (and vice versa). ${ }^{10}$ Doing so enables further tuning of surface properties of the nanoparticles.

\section{Modification with biological molecules}

Biological molecules can be exploited for the functionalization of nanoparticles. GNP conjugates bring together the unique properties and functionalities of both materials (eg, strong plasmon absorption bands, light scattering of the nanoparticles, and the ability of biological molecules to achieve high specific binding by molecular recognition). ${ }^{8}$ Several ways have been utilized to attach biological molecules to nanoparticles. Among these, using the electrostatic interactions between the GNPs and the biological molecules is one of the easiest ways to functionalize and stabilize GNP bioconjugates. For example, when GNPs are positively charged, they bind by stable ionic interactions to negatively charged and nucleophilic moieties. Specifically, GNPs may interact with the phosphate ester backbone of nucleic acids, ${ }^{11}$ electron-dense regions of poly(amidoamine) dendrimers, ${ }^{12}$ or negatively-charged carboxylate groups..$^{13}$ The molecular mass of the biological molecule and the overall charge of its functional groups are important in this regard. Biological molecules containing simultaneous acidic and basic groups (for example, proteins) are efficient in stabilizing GNPs. ${ }^{14}$ In general, it is commonly accepted that stabilization of GNPs by biological molecules occurs through passive adsorption of the biological molecule onto the nanoparticle surface by electrostatic and hydrophobic interactions. A strong negative charge on the citrate-stabilized GNP surface provides opportunity for Coulombic interaction with $\mathrm{NH}_{2}$ groups of lysine residues of proteins adsorbed on the nanoparticle surface.

Thiolated biomolecules can directly be bound on GNP surface via thiol-gold affinity interactions. DNA-GNP aptamers have been created for recognition of thrombin, ${ }^{15}$ platelet-derived growth factors, ${ }^{16}$ and cancer-associated epitopes. ${ }^{17}$ In addition, biological molecules that have a functional group which can bind to the gold surface (like thiols or specific peptide sequences) can replace some of the original stabilizer molecules when they are added directly to the particle solution. In this way, molecules like oligonucleotides, peptides, or PEG can be readily linked to GNPs. ${ }^{18-20}$

The advantage of physical adsorption is that the nanoparticles have a minimum effect on the structure and function of the biological molecule. With native structure intact, the activity, selectivity, and specificity of the biological molecule towards a particular target are largely unaffected. However, the drawback of this approach is the possibility of downstream desorption of the biological molecules from the GNP surface. Therefore, characterization of synthesized conjugates is necessary, in particular to rule out aggregation effects or unspecific binding during the conjugation process.

Alternatively, biological molecules can also be attached to the shell of stabilizer molecules around the GNPs by bioconjugate chemistries. The most common protocol is the covalent linkage of amino groups on the biological molecules with carboxyl groups at the free ends of stabilizer molecules by using 1-ethyl-3-(3-dimethylaminopropyl) carbodiimide HCl-mediated reaction. ${ }^{21}$ Using this protocol, almost all kinds of biological molecules can be attached to the nanoparticle surface (Figure 3). This so called "click chemistry" has been shown to give GNPs molecule-specific binding sites, such as for biotin-streptavidin (SA) linking ${ }^{22}$ and azide-linking. ${ }^{23}$ For proteins, azide linkages have created GNPs with fully functional lipases from Thermomyces lanuginosus. ${ }^{24}$

A variety of macrostructures can form when various gold nanomaterials assemble with biomolecules. Different methods for preparing various GNPs provide scientists with a "bottom-up" approach to materials synthesis where the scientists engineer the building blocks and the macrostructures build themselves. ${ }^{2}$ Although this approach is not yet in

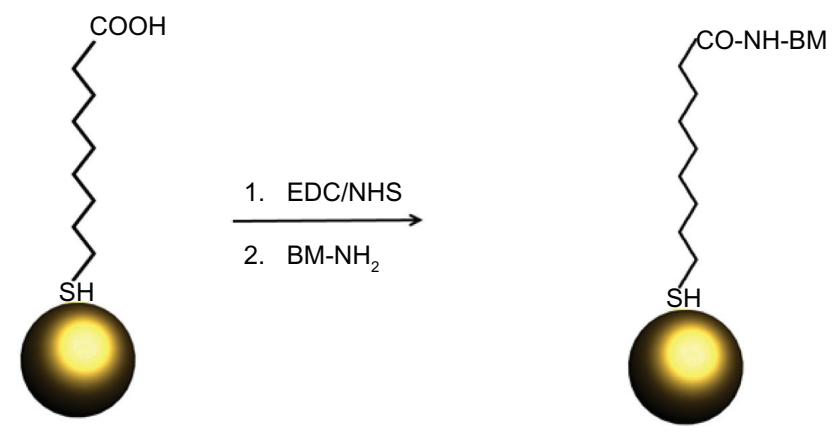

Figure 3 Reaction scheme for the EDC-mediated functionalization of gold nanoparticles.

Abbreviations: BM, biomolecule; EDC, I-ethyl-3-(3-dimethylaminopropyl) carbodiimide hydrochloride; NHS, N-hydroxisuccinimide. 
widespread usage for nucleic acids, protein-functionalized GNPs can self-arrange into monolayers and provide a scaffold onto which arrays of enzymes attach. Controlling interparticle proximity by changing the length of DNA linkers allows for elaborate monolayer construction such as sheets with evenly spaced wells. ${ }^{25}$ These monolayers can also be stacked and arranged in alternating molecular patterns through layerby-layer deposition. ${ }^{26-28}$

Another means that may be amenable for attaching macromolecular DNA or RNA is by coating the gold surface with alternating layers of cationic and anionic polyelectrolytes. ${ }^{29}$ Synthesizing DNA or peptide linkers between GNPs confer these building blocks with programmable spatial coordinates. This can give an exquisite level of control, as the polymerase chain reaction can be performed directly on the surface of GNPs for this kind of organization. ${ }^{18}$ Any or all of these approaches may potentially be modified for gene or RNA stabilization and delivery as well, though remain to be tested. The possibilities for functionalization upon GNPs are vast. These are just a portion of the reported functionalization methods and types of groups that have been attached to GNPs. New ways of functionalization and different types of group attachment are subjects of an intensely growing area of nanotechnology research.

\section{Characterization}

Functionalized GNPs behave in a variety of fashions depending on their size, charge, shape, concentration, and differences in bound ligands. ${ }^{30-32}$ Methods for quantifying these properties include the detection of electrical, optical, and photothermal emission and absorption, mobility shift, and size differences. GNPs can be characterized by their localized surface plasmon resonance (LSPR), whereby free electrons oscillate in response to light stimulation. This resonance can manifest as light scattering, which is detectable by spectroscopy. At certain wavelengths, light absorption produces heat instead of scattering. Field coupling between adjacent GNPs produces distance-dependent disturbances in their LSPR which allows for characterization of interparticle proximity. ${ }^{33}$ The addition of groups to GNPs can result in the formation of heterogeneous products. Distinctive bands corresponding to the number of oligonucleotides bound to GNPs have been shown by gel electrophoresis. ${ }^{34,35}$

The distribution of GNPs with varying levels of conjugation can be quantified by high-performance liquid chromatography (HPLC). Theoretical models have been devised to predict the approximate heterogeneity of a given GNP-ligand solution. ${ }^{36}$ Since the melting temperature $\left(T_{\mathrm{m}}\right)$ of GNP-DNA conjugates is size-dependent, they can be separated based on size from a heterogenous solution via serialized centrifugation at successively lower temperatures ${ }^{37}$ GNPs can also be characterized by size according to their electron dynamics in response to photoexcitation where absorption of light can cause the "bleaching" of surface plasmon interband transitions. ${ }^{38}$ Adsorption of molecules to gold nanorods (GNRs) can be confirmed by surface-enhanced Raman scattering, Fourier transform infrared spectroscopy, X-ray photoemission spectroscopy, nuclear magnetic resonance (NMR), dynamic light scattering, and fluorescence spectroscopy. $5,6,39$ Since GNPs less than $2 \mathrm{~nm}$ in size have different electron distributions than larger nanoparticles, the application of agents that bind to the surface of those particles will follow different collisional models for quenching. This allows for characterizing the transition of nanoparticles to free atoms in suspension and confirming their binding to ligands. ${ }^{40}$ Quartz crystal microbalance (QCM) is yet another technique successfully used to compare the binding affinity of GNPs to different ligands. ${ }^{41}$

\section{Stabilization}

The literature relates stabilization properties to functionalized GNPs that demonstrate the ability to prevent molecular aggregation and/or degradation. Our interests are more focused on the ability of the nanomaterial to prevent nucleic acids and other conjugates from degradation. DNA-GNP complexes exhibit unique properties and increase stabilization in the presence of DNA hydrolyzing enzymes in physiological conditions. ${ }^{42}$ Current research illustrates various factors that prove to have significant relevance to the degree of stabilization, as well as techniques in which stabilization may be achieved.

In terms of physical stabilization, GNRs can be coated by cetyltrimethylammonium bromide to form stable lattices of different shapes such as honeycombs and square tiles. ${ }^{43}$ Zeta-potential measurements of ligands bound to GNPs can be used to confirm stabilization as this is a mode of detecting the magnitude of repulsion between particles and thus their propensity to aggregate. ${ }^{44}$ Peptide chemistries, in addition to assembly advantage, may also provide stabilization. ${ }^{45} \mathrm{SA}$ protein displays relatively superior biomolecular-colloidal stability for the purpose of antisense oligonucleotide delivery involving cellular penetration by way of signaling peptide sequences from viruses. ${ }^{46}$ Evidence suggests that increased density in an oligonucleotide conjugated to a GNP correlates to increased stabilization, likely as a result of interference of high surface charge densities on foreign nucleic acid recognition enzymes that are involved in the immune 
response. ${ }^{47}$ Similar to the effects of oligonucleotide density, multidentate peptide ligands have shown positive potential. ${ }^{45}$ Stability of DNA on GNPs has been reported to be sequencespecific with different nucleosides having different binding affinities to the assemblage. ${ }^{42}$ Immobilization of DNA onto gold has also been reported to enhance its thermal stability. ${ }^{48}$

Polyvalent and PEGylation approaches are also reported to stabilize DNA in conjunction with gold. ${ }^{49,50}$ For example, PEG, possessing a pentaethylenehexamine at one end of each polymer chain (N6-PEG), acts as a surface-modifier in cooperation with the cations of salts in physiological conditions to reinforce the formation of the GNPs. In addition, immobilization of the PEG-derived substances on the modified surfaces results in the high-level stabilization of the GNPs. ${ }^{51}$ Amphiphile DNA micelles, and/ or electrostatic assembly and peptide capping, also have a bearing on particle and DNA stabilization. ${ }^{52-54}$ The stabilizing effects of protein folding, which are dependent upon length, hydrophobic properties, and electrostatic charge, imply applications for peptide capping ligands for DNA/ GNP-complex stabilization. ${ }^{54}$

Nanoparticles developed into DNA triple helices require the presence of stabilizing triplex DNA binding molecules to assemble, due to the thermal instability of the triple helix at room temperature. ${ }^{55}$ The common laboratory technique of centrifugation has recently been explored as a means to polarize GNP clusters, which facilitates the attraction and electrical conductivity between the molecules and results in more stable linear assemblages. ${ }^{56}$ Laser irradiation, accompanied by ionization and $\mathrm{pH}$ shifts, is a technique which may stabilize GNPs that are functionalized with a single layer of thiobarbituric acid (TBA) through dimensional reduction, as well as the inherent reinforcing properties of TBA. ${ }^{57}$

\section{DNA delivery}

The application of functionalized GNP-DNA conjugates in therapeutics is reliant upon efficient and successful delivery. Surface-functionalization here also affords controlled release and exquisite control of their activity and uptake into cells. From a physiochemical standpoint, the GNP primarily serves as the delivery agent, not the effector, as the ability to add noncovalent stable groups to GNPs makes it easier to dissociate the two inside the cell. GNPs have been shown to dissociate from conjugated groups by laser-induced, ultrafast thermal changes, ${ }^{58}$ potentially allowing for in vivo controlled release without micromanaging local disturbances in the molecular environment. Although, once again, much of the work has focused on DNA, controlled release has been accomplished via optical or electrochemical methods. ${ }^{59-62}$

Remotely controlled GNPs with near-infrared illumination have demonstrated their potential as optical switches for gene delivery by use in releasing gene-interfering DNA oligonucleotides. ${ }^{54}$ Another method for optical activation uses UV light as a means for illumination, activating the release of a biologically inhibiting caging group from a functional amino acid sequence covalently attached to a nanoparticle and thus permitting the nanocomplex to bind to a cell. ${ }^{61}$ Nanoparticle bioconjugates confined to patterned gold electrodes by thiol bonds have shown both the means to control the electrochemical release of nanoparticle conjugates as well as the ability to restore the electrodes used by the same conjugation mechanism by way of the reductive secretion of endogenously constructed monolayers which allow for regulated release and regeneration of materials. ${ }^{62}$

To date, there has been much more focus on publications discussing the chemistry and functionalization of GNPs for diagnostic applications than for DNA delivery. For example, much of the work on GNPs and DNA is aimed at chemical detectors and monitors, or so-called GNPs as chemical "antennas", for DNA. This includes work looking at particle radius ${ }^{63}$ for the purpose of hybridizing DNA linkers onto the gold surface, ${ }^{64}$ aggregation and disaggregation, or selective desorption. ${ }^{65}$ Fluorescence-based methods, ${ }^{66}$ or others specific for DNA sequences, ${ }^{67}$ can allow for detection at very low concentrations with enhanced sensitivity. ${ }^{1}$ GNPs possess different optical properties based on their distance from each other. Mirkin and coworkers have prepared and verified the length of oligonucleotides by attaching them to GNPs and correlating the absorbance of the resulting mixture with the length of the DNA between them. This assay is particularly sensitive and capable of detecting DNA at the femtomolar level. ${ }^{1}$

In recent years, investigators have begun applying their knowledge of GNP chemistry and functionalization to the difficult challenge of DNA delivery. One seminal paper by Chithrani et $\mathrm{al}^{68}$ determined size and shape dependence of GNP uptake into human cells. Another critical factor in delivery is the loading efficiency of the nucleic acid, which has been optimized for DNA oligonucleotides onto GNPs. ${ }^{69}$ An alternative approach has been to load genes onto a GNP surface functionalized with amino acids or dendrimeric derivatization. ${ }^{70}$ Another approach that we and others have taken is to deliver the nanoparticles with the gene as passenger complexes bound to gold microparticles. ${ }^{71,72}$ We have shown this to achieve bioactive delivery of a nanoparticle DNA vaccine. A variety of surface functionalizations of GNPs have 
been attempted to improve uptake $\mathrm{e}^{72,73}$ as well as intracellular distribution, ${ }^{74}$ including derivatization with sugar, ${ }^{75,76}$ lighttriggered chemistries, ${ }^{77}$ and others. ${ }^{78}$ Finally, one recent and exciting direction is the functionalization of gold for the purpose of both targeting and tissue specificity in an attempt to induce robust bioactivities, such as immune responses. ${ }^{79}$ Such general approaches to nanoparticle-cell interaction and intracellular delivery are illustrated in Figure 4.

Nanoconjugations capable of reversing their assemblage have potential for drug delivery. The programmed disassembly is accomplished by DNA linkers containing mismatches at specified locations and yield efficient attachment and release from the surface of GNPs in a counterion-screened electric field. ${ }^{62}$ As mentioned in the stabilization section, amino acids show efficacy in DNA binding and delivery. Two specific biomolecular complexes utilizing lysine and lysine dendron functionality display sensitivity to glutathione levels within cells and, therefore, provide selective delivery and subsequent expression of DNA. ${ }^{70}$ A novel species of DNA block copolymer amphiphiles of typical micelle uniformity have been reported as potential mobilization agents for nanovesicles. ${ }^{52}$

Viruses, such as the Moloney murine leukemia virus, have been utilized as tools for delivery of nanoparticles into the cell cytosol. By extrusion, GNPs may be coated with virusderived membranes, thereby allowing them to bind and invade cells bearing particular viral receptor sites. ${ }^{79}$ Complexation of DNA to cationic glycopolymer-stabilized GNPs shows potential as a solution to the problems of endosomal withdrawal and nuclear uptake in gene delivery with their demonstrated

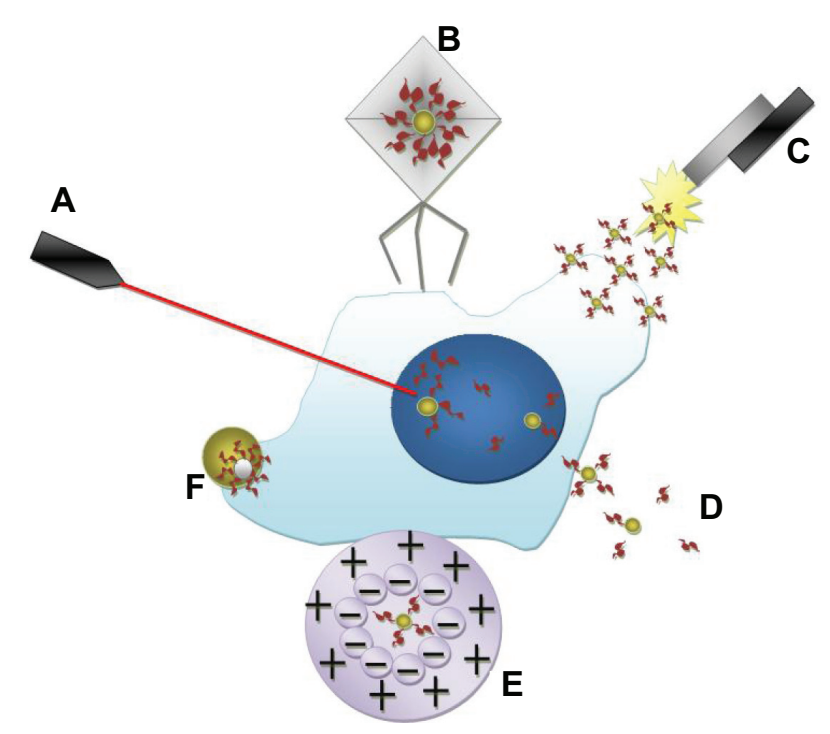

Figure $\mathbf{4}$ Gene delivery into a cell by $\mathbf{A}$ ) remote-controlled laser, B) viral membrane, C) biolistics, D) reverse assemblage, E) micelle, and F) nanoparticle bound to gold microparticle. [Not to scale] reluctance to aggregate in and ability to associate well in physiological conditions. ${ }^{75}$ Transfection efficiencies of cationic glyconanoparticles display a size-dependency in their efficiency as gene delivery agents. ${ }^{76}$

A biolistic method for the delivery of nucleic acids via cationic microparticles and nanoparticles has been declared to be less complex to carry out than the common calcium/spermidinebased strategy, and purportedly displays a remarkably efficient nucleic acid binding ability and functioning dependent upon concentration. ${ }^{71}$ Correlating with factors of stabilization, the oligonucleotide density on the surface of the particles is directly proportional to uptake efficiency, thereby inferring that the more proteins stabilizing the nanoparticle, the greater the probability of successful uptake. ${ }^{46}$ Also similar to stabilization characteristics is the importance of dimensional and electrical properties of nanoparticles in the delivery of therapeutic substances such as DNA or RNA. As shown in delivery to the gastrointestinal tract, larger-sized particles provided a greater surface area for functionalization with polymer chains which, through the subsequently enhanced stabilization, allowed for greater cellular uptake in the tested epithelial cells.

The polarity of the particles also contributed to the delivery efficiency, with positively-charged GNPs displaying highest deliverance potential and the negatively-charged GNPs showing greater cellular uptake than neutral GNPs, which was likely due to their affinity for membrane proteins. ${ }^{76}$ Specifically, for DNA binding and cell uptake, biocompatible GNPs have been touted, so-called positively-charged colloidal gold nanoparticles (PGN). PGNs were shown to deliver interleukin-2 plasmid DNA and to elicit significant expression in mice. ${ }^{80}$ GNPs grafted with polyethyenimine showed enhanced delivery of plasmid and importantly these retained activity in the presence of serum which is usually a great limitation for liposomal or polymeric delivery. ${ }^{81}$ Importantly for cell uptake, coating the surface of GNP with PEG impacted endocytosis and intracellular trafficking pattern altering it relative to traditional citratestabilized GNP. In this work, the authors found that PEG-GNP was found in both cytosol and smaller intracellular vesicles, unlike citrate-stabilized GNP. ${ }^{82}$ The plasma membrane is the first surface that the GNPs encounter and recently it has been shown that the surface charge of the GNP which was modulated by the attachment of cationic or anionic moieties can alter a cell's membrane potential and depending on the cell type can affect cell proliferation, viability, and apoptosis. ${ }^{83}$

\section{RNA delivery}

Free, unmodified small interfering RNA (siRNA) is notoriously unstable and sensitive to nucleases when delivered 
into nonembryonic mammalian cells. ${ }^{84,85} \mathrm{~A}$ variety of chemically modified siRNAs, especially methylation at the $2^{\prime}$-OH hydroxyl group, ${ }^{86}$ peptide conjugation, ${ }^{87}$ or PEGylation, ${ }^{88}$ have partly addressed the stability issue. However, attachment of siRNA to GNPs or other nanomaterials will provide important delivery as well as stabilization advantages, ideally without excessively modifying the oligo- or nanoparticle. GNPs may also possess a more efficient loading or assemblage for accomplishing RNA interference, since the radial arrangement of siRNA about the surface of a GNP uniquely creates extra working area per unit particle. Although it is possible to unload siRNA from the GNP by laser stimulation inside the cell, it is not necessary because researchers have successfully triggered RNA interference without that step.

Experiments with GNPs coated with siRNA via thiolmodified oligoethylene glycol bridges have allowed for Luciferase knockdown in HeLa cells without affecting cell viability ${ }^{89}$ For efficacy, a layer-by-layer approach to siRNA deposition onto GNPs has been developed for identical unit preparation; also showing successful delivery into cells..$^{90}$ It is interesting that both gene therapy and siRNA experiments have shown success in cells without direct attempts to liberate the RNA from the complex. Further experiments may clarify how a RISC loading complex is able to interact with siRNA on a GNP and whether it is capable of dissociating them or forming a cluster of multiple catalytic sites. In addition to more research required on GNPs in terms of their advantages for cell entry and protection of the RNA molecules from degradation, other possible limitations may be endosomal release and/or nuclear delivery as well known for other systems.

There is intense interest in GNP delivery of nucleic acids to induce immune response and this has been shown recently for GNRs and their delivery of single-stranded RNA (5'-PPP-ssRNA) ${ }^{91}$ Another double-stranded RNA (dsRNA) molecule, polyinosinic:polycytidilic acid (poly I:C) has been extensively clinically tested and there is a great deal of interest in its formulation via nanoparticles since it is such a powerful immunostimulant and activator of toll-like receptor. ${ }^{92,93}$

\section{Conclusion and future}

In summary, Table 1 presents an overview of the wide variety of approaches used by researchers to date in order to functionalize GNPs for the purpose of binding, stabilizing, and delivery of DNA, RNA, and other biological macromolecules. This includes methods such as adding various sulfur and linker chemistries, amino acids and peptides, ligand exchange, electrostatic interactions, etc in order to create a surface which will bind these macromolcules. A variety of factors have now been identified which upon such functionalization will influence the bioactivity of the GNPs. This includes their size, shape, charge and electron density, concentration, solvent, spatial coordinates, $\mathrm{pH}$, and of course their method of preparation. Characterization chemistries are another important area of active research including but not limited to light scatter and a variety of spectroscopic and fluorimetric techniques, plasmon resonance, infra red and X-ray spectroscopy, QCM, centrifugation, gel electrophoresis, HPLC, and NMR.

There are still, however, a number of challenges or obstacles to be overcome for GNPs to reach their full potential as delivery reagents for therapeutic DNA, RNA, and other macromolecules. Despite the apparent breakthrough of getting siRNA into the cell and preserving its integrity, structure, and activity, the toxic effects of different GNPconjugates elicit mixed results depending on particle size and other factors. ${ }^{81-83}$ This is problematic, but development of safe GNP-siRNA delivery complexes is hopeful and research is ongoing. It has been shown that macrophages will internalize GNPs without triggering the inflammatory response, ${ }^{91}$ though the final excretory fate in multicellular organisms is still under study. Clinical trials for other siRNA delivery systems such liposomes, polymers, nongold cationic polyelectrolyte complexes, and virus-based vectors have been delayed because of their variability in cytotoxicity tests, ${ }^{92}$ so research into GNP-conjugation offers a promising alternative. For the moment it seems that gene therapy in humans is realizable, if not with GNPs then with another agent, drawing from similar chemistries.

In conclusion, a variety of conjugation chemistries for modifying surfaces have resulted in the fabrication of many GNP derivatives with multifunctional purposes. Applications of these range from homing devices and molecular "antennae" to platforms for the delivery of drugs of all kinds, including DNA. In the case of drug and gene delivery for GNRs, this was recently reviewed by Pissuwan et al. ${ }^{93}$ With advances in surface chemistry, there come novel applications for characterizing the GNP bionanoconjugates such as plasmon absorption, light scatter and other optical methods, QCM, electrophoresis and HPLC, and many more. Certainly for protein GNP bioconjugates, these chemistries are now well established, though they do not ensure conjugate enhancement. A conformational change in the biomolecule in response to GNP binding or functional group linkage could 
Table I Summary of the approaches, variables, characterization and obstacles for GNPs

\begin{tabular}{|c|c|c|c|c|}
\hline & Methods/approaches & Variables & Characterization ${ }^{29-40}$ & Obstacles \\
\hline Functionalization $^{7-14}$ & $\begin{array}{l}\text { Adding functional groups } \\
\text { and biological molecules } \\
\text { Electrostatic repulsion } \\
\text { Ligand exchange }\end{array}$ & $\begin{array}{l}\text { Size, shape, charge, and } \\
\text { electron density } \\
\text { Concentration } \\
\text { Type of ligands } \\
\text { Solvent }\end{array}$ & $\begin{array}{l}\text { Plasmon absorption bands } \\
\text { Light scattering } \\
\text { High specific binding }\end{array}$ & $\begin{array}{l}\text { Preservation of ligand } \\
\text { properties } \\
\text { Improving effector } \\
\text { kinetics }\end{array}$ \\
\hline Binding ${ }^{11-29}$ & $\begin{array}{l}\text { lonic attachment } \\
\text { Azide and other "click" chemistries } \\
\text { Thiol-mediated binding } \\
\text { Biotin-avidin linkage } \\
\text { Peptide linkage } \\
\text { Nucleic acid/peptide } \\
\text { aptamers }\end{array}$ & $\begin{array}{l}\text { Size, shape, charge, } \\
\text { and electron density } \\
\text { Interparticle proximity } \\
\text { Composition } \\
\text { Binding specificity } \\
\text { Electrostatic interactions } \\
\text { Programmable spatial } \\
\text { coordinates by DNA } \\
\text { or peptide linkers }\end{array}$ & $\begin{array}{l}\text { Absorption difference } \\
\text { spectroscopy, } \\
\text { Fluorescence, X-ray, IR, } \\
\text { SERS, DLLS, and Mie } \\
\text { scattering of LSPRs } \\
\text { (optical methods) } \\
\text { QCM } \\
\text { Centrifugation } \\
\text { Gel electrophoresis } \\
\text { HPLC } \\
\text { NMR }\end{array}$ & $\begin{array}{l}\text { Steric hindrance } \\
\text { Solubility } \\
\text { Electrostatic } \\
\text { compatibility } \\
\text { Binding affinity }\end{array}$ \\
\hline Stabilization ${ }^{42-57}$ & $\begin{array}{l}\text { Cetyltrimethylammonium bromide } \\
\text { Capping of nucleic acids } \\
\text { Multidentate peptide ligands } \\
\text { SA protein } \\
\text { Citrate-stabilized gold hydrosols } \\
\text { Quaternary ammonium chains } \\
\text { N6-PEG } \\
\text { TBA } \\
\text { Cationic glycopolymers }\end{array}$ & $\begin{array}{l}\text { Size, shape, charge, } \\
\text { and electron density } \\
\mathrm{pH} \\
\text { Sequence specificity } \\
\text { Surface chemistry } \\
\text { Method of assembly } \\
\text { Oligonucleotide composition } \\
\text { Hydrophobic properties } \\
\text { Quantity of conjugates } \\
\text { Saturation concentration } \\
\text { Preparation method }\end{array}$ & $\begin{array}{l}\text { Size and zeta-potential } \\
\text { by DLLS } \\
\text { Other optical methods } \\
\text { Centrifugation }\end{array}$ & $\begin{array}{l}\text { Aggregation } \\
\text { Heterogeneity }\end{array}$ \\
\hline Delivery ${ }^{46,52,54,58-84}$ & $\begin{array}{l}\text { Epitope and intracellular targeting } \\
\text { by peptides } \\
\text { DNA block copolymer amphiphiles } \\
\text { Virus-derived membrane transporters } \\
\text { Biolistic particle delivery } \\
\text { Electrochemically, optically, } \\
\text { and/or enzymatically induced ligand } \\
\text { dissociation } \\
\text { Reversible assemblage } \\
\text { of groups }\end{array}$ & $\begin{array}{l}\text { Size, shape, charge, and } \\
\text { electron density } \\
\text { Interspatial coordinates } \\
\text { Loading efficiency } \\
\text { Oligonucleotide composition }\end{array}$ & $\begin{array}{l}\text { Optical methods } \\
\text { Blotting techniques }\end{array}$ & $\begin{array}{l}\text { Toxicity and reactivity } \\
\text { Biocompatibility } \\
\text { Excretability } \\
\text { Susceptibility of nucleic } \\
\text { acids to degradation }\end{array}$ \\
\hline
\end{tabular}

Abbreviations: SA, streptavidin; PEG, poly(ethylene glycol); TBA, thiobarbituric acid; QCM, quartz crystal microbalance; HPLC, high-performance liquid chromatography; NMR, nuclear magnetic resonance; SERS, surface-enhanced Raman scattering; LSPR, localized surface plasmon resonance.

enhance, stabilize, or reduce its activity as can be seen by studies on different complexes. ${ }^{24}$ Research in our lab and many others across the world is now engaged in determining whether these conjugation and characterization chemistries and approaches for stabilization and delivery can be applied to DNA vaccines and therapeutic RNA molecules, such as siRNA, splice-site switching oligomers, the double-stranded RNA immunostimulant polyinosinic polycytidilic acid (poly I-C), RNA vaccines, and others. It is clear that these nucleic acid nanoparticles have very potent and specific bioactivities and represent a powerful new generation with potential for molecular therapy stabilized and delivered via the emerging exciting field of biomedical nanotechnology.

\section{Acknowledgment}

Dr Wanekaya and Dr DeLong are supported by an AREA/ R15 grant from the National Cancer Institute entitled, "Anticancer RNA Nanoconjugates” (1 R15 CA139390-01).

\section{Disclosure}

The authors report no conflicts of interest in this work.

\section{References}

1. Elghanian R, Storhoff JJ, Mirkin CA, et al. Selective colorimetric detection of polynucleotides based on the distance-dependent optical properties of gold nanoparticles. Science. 1997;277:1078-1081.

2. Shenhar R, Rotello VM. Nanoparticles: scaffolds and building blocks. Acc Chem Res. 2003;36:549-561. 
3. Cheon J, Lee JH. Synergistically integrated nanoparticles as multimodal probes for nanobiotechnology. Acc Chem Res. 2008;12:1630-1640.

4. Goel R, Shah N, Visaria R, Paciotti GF, Bischof JC. Biodistribution of TNF- $\alpha$-coated gold nanoparticles in an in vivo model system. Nanomedicine (Lond). 2009;4:401-410.

5. Nikoobakht B, El-Sayed MA. Surface-enhanced Raman scattering studies on aggregated gold nanorods. J Phys Chem A. 2003;107:3372-3378.

6. Jans $\mathrm{H}$, Liu X, Huo Q, et al. Dynamic light scattering as a powerful tool for gold nanoparticle bioconjugation and biomolecular binding studies. Anal Chem. 2009;81:9425-9432.

7. Duboisand LH, Nuzzo RG. Synthesis, structure, and properties of model organic surfaces. Annu Rev Phys Chem. 1992;43:437-463.

8. Uson R. The chemistry of gold. Synthesis and Reactivity in Inorganic, Metal-organic, and Nano-metal Chemistry. 1978;8:503-504.

9. Kanaras AG, Kamounah FS, Brust M, et al. Thioalkylatedtetraethylene glycol: a new ligand for water soluble monolayer protected gold clusters. Chem Commun. 2002;20:2294-2295.

10. Pellegrino T, Kudera S, Parak W, et al. On the development of colloidal nanoparticles towards multifunctional structures and their possible use for biological applications. Small. 2005;1:48-63.

11. Park SY, Lee JS, Mirkin CA, et al. Structures of DNA-linked nanoparticle aggregates. J Phys Chem B. 2006;110:12673-12681.

12. Xiangyang S, Suhe W, Baker JR. Dendrimer-entrapped gold nanoparticles as a platform for cancer-cell targeting and imaging. Small. 2007;3:1245-1252.

13. Kariuki NN, Luo J, Zhong CJ, et al. Assembly of bimetallic gold-silver nanoparticles via selective interparticle dicarboxylate-silver linkages. Chem Mater. 2005;18:123-132.

14. Mayer AR, Mark JE. Colloidal Gold Nanoparticles Protected by Cationic Polyelectrolytes. J Macromol Sci A. 1997;34:2151-2164.

15. Cho H, Baker BR, Tok JH, et al. Aptamer-based SERRS sensor for thrombin detection. Nano Lett. 2008;8:4386-4390.

16. Huang CC, Huang YF, Chang HT, et al. Aptamer-modified gold nanoparticles for colorimetric determination of platelet-derived growth factors and their receptors. Anal Chem. 2005;77:5735-5741.

17. Medley CD, Smith JE, Tan W, et al. Gold nanoparticle-based colorimetric assay for the direct detection of cancerous cells. Anal Chem. 2008;80:1067-1072.

18. Chen W, Bian A, Kotov A, et al. Nanoparticle superstructures made by polymerase chain reaction: collective interactions of nanoparticles and a new principle for chiral materials. Nano Lett. 2009;9:2153-2159.

19. Otsuka H, Nagasaki Y, Kataoka K. PEGylated nanoparticles for biological and pharmaceutical applications. Adv Drug Deliv Rev. 2003;55:403-419.

20. Lévy R, Wang Z, Brust M, et al. A generic approach to monofunctionalized protein-like gold nanoparticles based on immobilized metal ion affinity chromatography. Chem Bio Chem. 2006;7:592-594.

21. Sperling RA, PellegrinoT, Parak WJ, et al. Electrophoretic separation of nanoparticles with a discrete number of functional groups. Adv Func Mater. 2006;16:943-948.

22. Aslan K, Luhrs C, Pérez-Luna V. Controlled and reversible aggregation of biotinylated gold nanoparticles with streptavidin. J Phys Chem B. 2004;108:15631-15639.

23. Gole A, Murphy CJ. Azide-derivatized gold nanorods: functional materials for "Click" chemistry. Langmuir. 2008;24:266-272.

24. Brennan J, Hatzakis N, Brust M, et al. Bionanoconjugation via click chemistry: the creation of functional hybrids of lipases and gold nanoparticles. Bioconjug Chem. 2006;17:1373-1375.

25. Wang L, Luo J, Schadt M, Zhong CJ. Thin film assemblies of molecularly-linked metal nanoparticles and multifunctional properties. Langmuir. 2010;26:618-632.

26. Wang Z, Lévy R, Fernig DG, Brust M. The peptide route to multifunctional gold nanoparticles. Bioconjug Chem. 2005;16:497-500.

27. Shi L, Lu Y, Shen J, et al. Site-selective lateral multilayer assembly of bienzyme with polyelectrolyte on ITO electrode based on electric field-induced directly layer-by-layer deposition. Biomacromolecules. 2003;4:1161-1167.
28. Chen C, Zhang P, Rosi N. A new peptide-based method for the design and synthesis of nanoparticle superstructures: construction of highly ordered gold nanoparticle double helices. $J$ Am Chem Soc. 2008;130:13555-13557.

29. Gole A, Murphy CJ. Polyelectrolyte-coated gold nanorods: synthesis, characterization and immobilization. Chem Mater. 2005; 17:1325-1330

30. El-Sayed MA. Small is different: shape-, size-, and compositiondependent properties of some colloidal semiconductor nanocrystals Acc Chem Res. 2004;37:326-333.

31. El-Sayed MA. Some interesting properties of metals confined in time and nanometer space of different shapes. Acc Chem Res. 2001;34:257-264.

32. Kelly LK, Coronado E, Zhao LL, Schatz GC. The optical properties of metal nanoparticles: the influence of size, shape, and dielectric environment. J Phys Chem B. 2003;107:668-677.

33. Jain PK, Huang X, El-Sayed IH, El-Sayed MA. Noble metals on the nanoscale: optical and photothermal properties and some applications in imaging, sensing, biology, and medicine. Acc Chem Res. 2008;41:1578-1586.

34. Zanchet D, Micheel CM, Alivisatos P, et al. Electrophoretic isolation of discrete Au nanocrystal/DNA conjugates. Nano Lett. 2001;1:32-35.

35. Zanchet D, Micheel CM, Alivisatos P, et al. Electrophoretic and structural studies of DNA-directed Au nanoparticle groupings. $J$ Phys Chem B. 2002;106:11758-11763.

36. Mullen DG, Desai AM, Baker JR, et al. The implications of stochastic synthesis for the conjugation of functional groups to nanoparticles. Bioconjug Chem. 2008;19:1748-1752.

37. Lee JS, Stoeva SI, Mirkin CA. DNA-induced size-selective separation of mixtures of gold nanoparticles. J Am Chem Soc. 2006;128:8899-8903.

38. Ahmadi TS, Logunov SL, El-Sayed MA. Size-dependent electron dynamics of gold nanoparticles nanostructured materials. Nanostruct Mater. 1997;679:125-140.

39. Kumar A, Mandal S, Sastry M, et al. Investigation into the interaction between surface-bound alkylamines and gold nanoparticles. Langmuir. 2003; 19:6277-6282.

40. Landes CF, Braun M, El-Sayed MA. On the nanoparticle to molecular size transition: fluorescence quenching studies. J Phys Chem. 2001;105:10554-10558.

41. Brewer SH, Glomm WR, Franzen S, et al. Probing BSA binding to citrate-coated gold nanoparticles and surfaces. Langmuir. 2005;21:9303-9307.

42. Storhoff JJ, Elghanian R, Mirkin CA, Letsinger RL. Sequencedependent stability of DNA-modified gold nanoparticles. Langmuir. 2002;18:6666-6670.

43. Sau TK, Murphy CJ. Self-assembly patterns formed upon solvent evaporation of aqueous cetyltrimethylammonium bromide-coated gold nanoparticles of various shapes. Langmuir. 2005;21:2923-2929.

44. Kim T, Lee K, Gong MS, Joo SW. Control of gold nanoparticle aggregates by manipulation of interparticle interaction. Langmuir. 2005;21:9524-9528

45. Krpeti Z, Nativo P, Porta F, Brust MA. Multidentate peptide for stabilization and facile bioconjugation of gold nanoparticles. Bioconjug Chem. 2009;20:619-624.

46. Liu Y, Franzen S. Factors determining the efficacy of nuclear delivery of antisense oligonucleotides by gold nanoparticles. Bioconjug Chem. 2008;19:1009-1016.

47. Massich MD, Giljohann DA, Mirkin CA, et al. Regulating immune response using polyvalent nucleic acid-gold nanoparticle conjugates. Mol Pharm. 2009;6:1934-1940.

48. Akamatsu K, Kimura M, Sugimoto N, et al. A DNA duplex with extremely enhanced thermal stability based on controlled immobilization on gold nanoparticles. Nano Lett. 2006;6:491-495.

49. Seferos DS, Prigodich AE, Mirkin CA, et al. Polyvalent DNA nanoparticle conjugates stabilize nucleic acids. Nano Lett. 2009;9:308-311. 
50. Srivastava S, Frankamp BL, Rotello VM. Controlled plasmon resonance of gold nanoparticles self-assembled with PAMAM dendrimers. Chem Mater. 2005;17:487-490.

51. Furusho H, Kitano K, Hamaguchi S, Nagasaki Y. Preparation of stable water-dispersible PEGylated gold nanoparticles assisted by nonequilibrium atmospheric-pressure plasma jets. Chem Mater. 2009;21:3526-3535.

52. Li Z, Zhang Y, Fullhart P, Mirkin CA. Reversible and chemically programmable micelle assembly with DNA block-copolymer amphiphiles. Nano Lett. 2004;4:1055-1058.

53. Sastry M, Rao M, Ganesh K. Electrostatic assembly of nanoparticles and biomacromolecules. Acc Chem Res. 2002;35:847-855.

54. Lévy R, Thanh NK, Fernig DG, et al. Rational and combinatorial design of peptide capping ligands for gold nanoparticles. $\mathrm{J} \mathrm{Am} \mathrm{Chem}$ Soc. 2004;126:10076-10084

55. Han MS, Lytton-Jean AR, Mirkin CA. A gold nanoparticle based approach for screening triplex DNA Binders. $J$ Am Chem Soc. 2006;128:4954-4955.

56. Roca M, Pandya NH, Nath S, Haes AJ. Linear assembly of gold nanoparticle clusters via centrifugation. Langmuir. 2010;26: 2035-2041.

57. Peng Z, Walther T, Kleinermanns K. Influence of intense pulsed laser irradiation on optical and morphological properties of gold nanoparticle aggregates produced by surface acid-base reactions. Langmuir. 2005;21:4249-4253.

58. Jain Prashant K, Qian W, El-Sayed MA. Ultrafast cooling of photoexcited electrons in gold nanoparticle-thiolated DNA conjugates involves the dissociation of the gold-thiol bond. J Am Chem Soc. 2006; $128: 2426-2433$.

59. Petersen S, Barcikowski S. Conjugation efficiency of laser-based bioconjugation of gold nanoparticles with nucleic acids. J Phys Chem. 2009;113:19830-19835.

60. Lee SE, Liu GL, Kim F, Lee LP. Remote optical switch for localized and selective control of gene interference. Nano Lett. 2009;9:562-570.

61. Dvir T, Banghart MR, Kohane DS, et al. Photo-targeted nanoparticles. Nano Lett. 2010;10:250-254.

62. Mali P, Bhattacharjee N, Searson PC. Electrochemically programmed release of biomolecules and nanoparticles. Nano Lett. 2006;6:1250-1253.

63. Hill HD, Millstone JE, Banholzer MJ, Mirkin CA. The role radius of curvature plays in thiolated oligonucleotide loading on gold nanoparticles. ACS Nano. 2009;3:418-424.

64. Wong IY, Melosh NA. Directed hybridization and melting of DNA linkers using counterion-screened electric fields. Nano Lett. 2009;9:3521-3526.

65. Charrier A, Candoni N, Thibaudau F. DNA detection method based on the two-dimensional aggregation and selective desorption of nanoparticle probes. J Phys Chem B. 2006;26:12896-12900.

66. Demers Linette M, Mirkin Chad A, Thibaudau F. A fluorescence-based method for determining the surface coverage and hybridization efficiency of thiol-capped oligonucleotides bound to gold thin films and nanoparticles. Anal Chem. 2000;72:5535-5541.

67. Ray PC, Darbha GK, Balarezo A, et al. Gold nanoparticle based surface energy transfer probe for accurate identification of biological agents DNA. ACS Symp Ser. 2009;1016:115-129.

68. Chithrani BD, Ghazani AA, Chan WC. Determining the size and shape dependence of gold nanoparticle uptake into mammalian cells. Nano Lett. 2006;6:662-668.

69. Giljohann DA, Seferos DS, Mirkin CA, et al. Oligonucleotide loading determines cellular uptake of DNA-modified gold nanoparticles. Nano Lett. 2007;7:3818-3821.

70. Ghosh PS, Kim CK, Rotello VM, et al. Efficient gene delivery vectors by tuning the surface charge density of amino acid-functionalized gold nanoparticles. ACS Nano. 2008;2:2213-2218.

71. Svarovsky SA, Gonzalez-Moa MJ, Sykes K, et al. Self-assembled micronanoplexes for improved biolistic delivery of nucleic acids. Mol Pharm. 2009;6:1927-1933.
72. DeLong RK, Akhtar U, Sallee M, et al. Characterization and performance of nucleic acid nanoparticles combined with protamine and gold. Biomaterials. 2009;30:6451-6459.

73. Sandhu KK, McIntosh CM, Rotello VM, etal. Gold nanoparticle-mediated transfection of mammalian cells. Bioconjug Chem. 2002;13: 3-6.

74. Delong RK, Knowle R, Werner A. R4 peptide-pDNA nanoparticle coated HepB vaccine microparticles: sedimentation, partitioning, and spray freeze dry bioprocesses. J Nanosci Nanotechnol. 2006;6:2783-2789.

75. Ahmed M, Deng Z, Narain R, et al. Cationic glyconanoparticles: their complexation with DNA, cellular uptake, and transfection efficiencies. Bioconjug Chem. 2009;20:2169-2176.

76. Ahmed M, Deng Z, Narain R. Study of transfection efficiencies of cationic glyconanoparticles of different sizes in human cell line. ACS Appl Mater Interf. 2009;1:1980-1987.

77. Volodkin DV, Madaboosi N, Blacklock J, et al. Surface-supported multilayers decorated with bio-active material aimed at light-triggered drug delivery. Langmuir. 2009;25:14037-14043.

78. Liang M, Lin IC, Toth I, et al. Cellular uptake of densely packed polymer coatings on gold nanoparticles. ACS Nano. 2010;4:403-413.

79. Deniger DC, Kolokoltsov AA, Davey RA, et al. Targeting and penetration of virus receptor bearing cells by nanoparticles coated with envelope proteins of Moloney murine leukemia virus. Nano Lett. 2006;6:2414-2421.

80. Shukoor MI, Natalio F, Ksenofontov V, et al. Double-stranded RNA polyinosinic-polycytidylic acid immobilized onto gamma-Fe2O3 nanoparticles by using a multifunctional polymeric linker. Small. 2007;8:1374-1378.

81. Pan Y, Neuss S, Jahnen-Dechent W, et al. Size-dependent cytotoxicity of gold nanoparticles. Small. 2007;3:1941-1949.

82. Connor EE, Mwamuka J, Wyatt MD, et al. Gold nanoparticles are taken up by human cells but do not cause acute cytotoxicity. Small. 2005;1:325-327.

83. Leroueil PR, Hong S, Banaszak Holl MM, et al. Nanoparticle interaction with biological membranes: Does nanotechnology present a Janus face? Acc Chem Res. 2007;40:335-342.

84. Brondani V, Zhang H, Filipowicz W, et al. Specific interference with gene expression induced by long, double stranded RNA in mouse embryonalteratocarcinoma cell lines. Proc Natl Acad Sci U S A. 2001;98:14428-14433.

85. Paddison PJ, Caudy AA, Hannon GJ. Stable suppression of gene expression by RNAi in mammalian cells. Proc Natl Acad Sci U S A. 2002;99:1443-1448.

86. Czauderna F, Fechtner M, Kaufmann J, et al. Structural variations and stabilising modifications of synthetic siRNAs in mammalian cells. Nucleic Acids Res. 2003;31:2705-2716.

87. Mok H, Park TG. Self-crosslinked and reducible fusogenic peptides for intracellular delivery of siRNA. Biopolymers. 2008;89:881-888.

88. Kim HR, Kim IK, Park TG, et al. Cationic solid lipid nanoparticles reconstituted from low density lipoprotein components for delivery of siRNA. Mol Pharm. 2008;5:622-631.

89. Giljohann DA, Seferos DS, Mirkin CA, et al. Gene regulation with polyvalent siRNA-nanoparticle conjugates. $\mathrm{J}$ Am Chem Soc. 2009;131:2072-2073.

90. Elbakry A, Zaky A, Breunig M, et al. Layer-by-layer assembled gold nanoparticles for siRNA delivery. Nano Lett. 2009;9:2059-2064.

91. Shukla R, Bansal V, Sastry M, et al. Biocompatibility of gold nanoparticles and their endocytotic fate inside the cellular compartment: a microscopic overview. Langmuir. 2005;21:10644-10654.

92. Jeong JH, Mok H, Oh YK, Park TG. siRNA conjugate delivery systems. Bioconjug Chem. 2009;20:5-14.

93. Pissuwan D, Niidome T, Cortie MB. The forthcoming applications of gold nanoparticles in drug and gene delivery systems. J Control Release. Epub 2009.

94. Noh SM, Kim WK, Kim SJ, et al. Enhanced cellular delivery and transfection efficiency of plasmid DNA using positively charged biocompatible colloidal gold nanoparticles. Biochim Biophys Acta. 2007;5:747-752. 
95. Hu C, Peng Q, Chen F, Zhong Z, Zhuo R. Low molecular weight polyethylenimine conjugated gold nanoparticles as efficient gene vectors. Bioconjug Chem. 2010;5:836-843.

96. Arvizo RR, Miranda OR, Thompson MA, et al. Effect of nanoparticle surface charge at the plasma membrane and beyond. Nano Lett. Epub 2010.
97. Chakravarthy KV, Bonoiu AC, Davis WG, et al. Gold nanorod delivery of an ssRNA immune activator inhibits pandemic $\mathrm{H} 1 \mathrm{~N} 1$ influenza viral replication. Proc Natl Acad Sci U S A. 2010;22:10172-10177.

98. Stone GW, Barzee S, Snarsky V, et al. Nanoparticle-delivered multimeric soluble CD40 L DNA combined with Toll-like receptor agonists as a treatment for melanoma. PLoS One. 2009;4(10):e7334.

\section{Publish your work in this journal}

Nanotechnology, Science and Applications is an international, peerreviewed, open access journal that focuses on the science of nanotechnology in a wide range of industrial and academic applications. It is characterized by the rapid reporting across all sectors, including engineering, optics, bio-medicine, cosmetics, textiles, resource sustainability and science. Applied research into nano-materials, particles, nanostructures and fabrication, diagnostics and analytics, drug delivery and toxicology constitute the primary direction of the journal. The manuscript management system is completely online and includes a very quick and fair peer-review system, which is all easy to use.

Submit your manuscript here: http://www.dovepress.com/nanotechnology-science-and-applications-journal 